\title{
Drawback of Chimerism Analysis by XY-Fluorescence In situ Hybridization: Deception of a Relapse
}

\begin{abstract}
Chimerism is monitored by various methods in posttransplant patients. Interphase fluorescence in situ hybridization (FISH) for XY (sex) chromosomes is one of the methods commonly employed. It is a sensitive method in terms of the number of cells analyzed. Chimerism testing is done to detect graft rejection/failure which eventually may be a sign of relapse of the malignancy. The relapse of the disease initially happens in the marrow and then spreads to the peripheral blood. Hence, performing chimerism by XY-FISH in the peripheral blood may miss an early relapse. Here, we present one such case where there was $98 \%$ donor chimerism with the evidence of relapse in the bone marrow with all recipient metaphases in the bone marrow by conventional cytogenetics.
\end{abstract}

Keywords: Chimerism, posttransplant monitoring, XY-fluorescence in situ hybridization

\section{Introduction}

Chimerism is regularly monitored in posttransplant patients, and the presence of more than $95 \%$ chimerism indicates healthy graft function. ${ }^{[1]}$ The loss of chimerism on follow-up indicates graft failure which may be an early sign of disease relapse in the allogeneic stem cell transplantation (ASCT) for malignant disorders. Chimerism test can be performed in many ways. The most commonly applied method is the polymerase chain reaction (PCR) amplification of short tandem repeats (STR). In sex-mismatched transplants, interphase fluorescence in situ hybridization for $\mathrm{X}$ and Y chromosomes (XY-FISH) can be used to detect chimerism in transplants with opposite sex donors. We report a case of acute myeloid leukemia (AML) who had relapsed 2 years post-ASCT, in whom the chimerism analysis by XY-FISH was stable, but the conventional cytogenetics picked up the recipient cells in all mitoses.

\section{Case Report}

A 17-year-old girl presented to us with fever and on evaluation was diagnosed with AML intermediate risk. FLT3, NPM1, and $B C R-A B L 1$ were negative and conventional cytogenetics showed abnormality of short arm of chromosome 10 and long arm

\footnotetext{
This is an open access journal, and articles are distributed under the terms of the Creative Commons Attribution-NonCommercial-ShareAlike 4.0 License, which allows others to remix, tweak, and build upon the work non-commercially, as long as appropriate credit is given and the new creations are licensed under the identical terms.
}

For reprints contact: WKHLRPMedknow_reprints@wolterskluwer.com of chromosome 17 [46, XX, add (10) (p15), del (17)(q21) [16]/ 46, XX [4]]. She received first induction $3+7$ with daunorubicin (DNR) $60 \mathrm{mg} / \mathrm{m}^{2}$ for 3 days as 1 -h infusion and cytarabine $100 \mathrm{mg} / \mathrm{m}^{2}$ per day for 7 days as continuous infusion. She was in morphological remission at the end of first induction. She then received the second induction $3+7$ with DNR $45 \mathrm{mg} / \mathrm{m}^{2}$ (institutional protocol) followed by one cycle of intermediate-dose cytarabine with $1.5 \mathrm{~g} / \mathrm{m}^{2}$ for 6 doses. Then, she underwent ASCT with her brother as the donor, who was 10/10 human leukocyte antigen match. The conditioning used was fludarabine-melphalan. Posttransplant, she developed acute graft-versus-host disease (GVHD) of the gut which was steroid responsive.

Chimerism analysis done by XY-FISH on the peripheral blood at day 30 was $100 \%$ donor. Day 100 chimerism by XY-FISH was also $100 \%$. Cyclosporine was tapered and stopped at 4 months. Subsequently, chimerism was monitored once in 6 months by the peripheral blood XY-FISH, which was all $100 \%$. After a disease-free survival of 2 years, she was diagnosed with a relapse of AML. At the time of relapse, chimerism was $98 \%$ utilizing XY-FISH [Figure 1], but conventional cytogenetics showed $47 \mathrm{XX},+7, \mathrm{t}(10,17)$ del (6) in 20 metaphases [Figure 2].

How to cite this article: Kiran Kumar DV, Perumal Kalaiyarasi J. Drawback of chimerism analysis by XY-fluorescence in situ hybridization: Deception of a relapse. Indian J Med Paediatr Oncol 2020;41:621-3.
DVS Kiran Kumar, Jayachandran Perumal Kalaiyarasi

Department of Medical Oncology, Cancer Institute (WIA), Chennai, Tamil Nadu, India

Submitted: $13-\mathrm{Feb}-2020$ Revised: 11-Mar-2020 Accepted: 07-Apr-2020 Published: 29-Aug-2020

Address for correspondence: Dr. Jayachandran Perumal Kalaiyarasi,

Department of Medical Oncology, Cancer Institute (WIA), 38, Sardar

Patel Road, Guindy,

Chennai - 600 036, Tamil Nadu, India.

E-mail: dr.pkjayachandran@ gmail.com

Access this article online

Website: www.ijmpo.org

DOI: 10.4103/ijmpo.ijmpo_60_20 Quick Response Code:

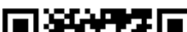




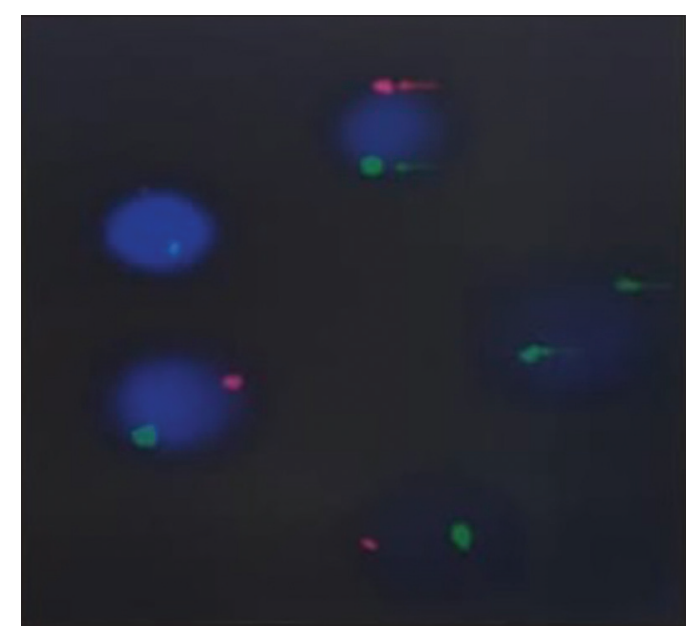

Figure 1: XY-Fluorescence in situ hybridization analysis of the peripheral blood at relapse; Probe used: Metasystems fluorescence in situ hybridization probe (XA X/Y); Green: chromosome X; Red: chromosome $\mathrm{Y}$ - This figure shows four cells with one red and green signals in each, which signifies those cells is from a male (XY). One cell in the 3'O clock position shows 2 green signals, which signifies that it belongs to a female (XX)

She received salvage with fludarabine, high-dose cytarabine, filgrastim chemotherapy and had refractory disease at the end of salvage, and subsequently, she succumbed to her illness.

\section{Discussion}

Analysis of chimerism levels can be used to monitor the proportion of donor and recipient cells after allogeneic hematopoietic stem cell transplant (HSCT). It can identify graft rejection and can predict early relapse and GVHD. ${ }^{[2]}$ There are various methods by which chimerism can be estimated. These include XY-FISH, conventional karyotyping, restriction fragment length polymorphism (RFLP), red blood cell phenotyping, analysis of STR by PCR, single nucleotide polymorphism analysis, and Y chromosome PCR. ${ }^{[3]}$

The sensitivity of XY-FISH for sex chromosomes is between $0.1 \%$ and $0.5 \%$ and conventional karyotyping is around $5 \%-10 \%$ for the detection of mixed chimerism. ${ }^{[3]}$ XY-FISH is done on interphase preparations with two differently labeled probes for $\mathrm{X}$ and $\mathrm{Y}$ chromosomes. It allows for rapid screening of many cells, and therefore, it is considered that high sensitivity can be achieved. Conventional cytogenetics depends on the culture of cells and analysis of mitoses and successful analysis depends on the presence of dividing cells and hence was considered to have low sensitivity. The relapse of leukemia initially starts in the bone marrow, and then, the leukemic cells spill over to the peripheral blood. Hence, in the context of detecting relapse, the sensitivity estimate of these methods is questionable. In the early stage of relapse, in the peripheral blood, the proportion of malignant cells is very low compared to the normal donor cells. Consequently, the analysis by XY-FISH would be done on majorly on donor cells which are in

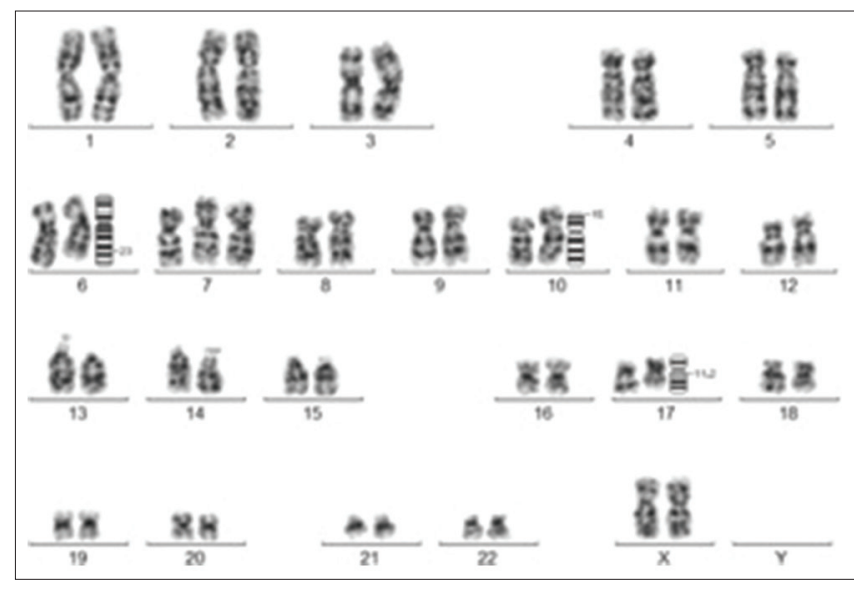

Figure 2: Conventional cytogenetics of bone marrow $-47 \mathrm{XX},+7, \mathrm{t}(10,17)$ del (6) [20/20]

the G0 phase, and hence, there is a chance to miss early relapse. Moreover, the leukemic cells tend to have a high proliferative index, and hence, an interphase FISH would miss such cells during analysis. However, in conventional cytogenetics, the cells will be cultured, which leads to the replication of the rapidly dividing malignant recipient cells as compared to the quiescent donor cells and hence analyze recipient malignant cells majorly. This is reflected in our patient where chimerism by XY-FISH in the peripheral blood was 98\% donor cells; however, the conventional karyotyping detected malignant recipient cells in all the mitoses.

Studies are done comparing XY-FISH to PCR analysis of $\mathrm{Y}$ chromosome-specific sequences and found that the XY-FISH missed a significant number of relapses compared to $\mathrm{Y}$ chromosome PCR. ${ }^{[4]}$ In conditions such as myelodysplastic syndrome and benign conditions such as pregnancy, XY-FISH is as good as conventional cytogenetics to detect chromosomal abnormalities. ${ }^{[5]}$ A study has been done for monitoring of chimerism posttransplant and was found that FISH is more sensitive. ${ }^{6]}$ However, studies have not been done comparing the utility of these in the context of detecting relapse after ASCT.

We conclude that, in the context of detecting relapse after allogeneic HSCT, XY-FISH might not be an ideal modality for analyzing chimerism. Conventional karyotyping, given its ability to select rapidly dividing cells, might be better when compared to XY-FISH, but karyotyping lacks sensitivity. Hence, more sensitive methods such as RFLP, STR PCR, variable number tandem repeat, and Y chromosome PCR which are the current standard of care should be considered in the context of ASCT for malignant disorders over XY-FISH.

\section{Declaration of patient consent}

The authors certify that they have obtained all appropriate patient consent forms. In the form the patient(s) has/have 
given his/her/their consent for his/her/their images and other clinical information to be reported in the journal. The patients understand that their names and initials will not be published and due efforts will be made to conceal their identity, but anonymity cannot be guaranteed.

\section{Financial support and sponsorship}

Nil.

\section{Conflicts of interest}

There are no conflicts of interest.

\section{References}

1. Stikvoort A, Sundin M, Uzunel M, Gertow J, Sundberg B, Schaffer $\mathrm{M}$, et al. Long-term stable mixed chimerism after hematopoietic stem cell transplantation in patients with non-malignant disease, shall we be tolerant? PLOS One 2016;11:e154737.

2. Balon J, Hałaburda $\mathrm{K}$, Bieniaszewska $\mathrm{M}$, Reichert $\mathrm{M}$, Bieniaszewski L, Piekarska A, et al. Early complete donor hematopoietic chimerism in peripheral blood indicates the risk of extensive graft-versus-host disease. Bone Marrow Transplant 2005;35:1083-8.

3. Van Deerlin VM, Reshef R. Chimerism testing in allogeneic hematopoietic stem cell transplantation. In: Leonard DG, editor. Molecular Pathology in Clinical Practice. Cham: Springer International Publishing; 2016. p. 823-48.

4. Koldehoff M, Steckel NK, Hlinka M, Beelen DW, Elmaagacli AH. Quantitative analysis of chimerism after allogeneic stem cell transplantation by real-time polymerase chain reaction with single nucleotide polymorphisms, standard tandem repeats, and Y-chromosome-specific sequences. Am J Hematol 2006;81:735-46.

5. He R, Wiktor AE, Durnick DK, Kurtin PJ, Van Dyke DL, Tefferi A, et al. Bone Marrow conventional karyotyping and fluorescence in situ hybridization: Defining an effective utilization strategy for evaluation of myelodysplastic syndromes. Am J Clin Pathol 2016;146:86-94.

6. Díez-Martín JL, Llamas P, Gosálvez J, López-Fernández C, Polo N, de la Fuente MS, et al. Conventional cytogenetics and FISH evaluation of chimerism after sex-mismatched bone marrow transplantation (BMT) and donor leukocyte infusion (DLI). Haematologica 1998;83:408-15. 